\title{
A Study of Effect of BMI on Pulmonary Function Tests in Young Individuals at Rajkot City
}

\author{
Dr. Ashvin Sorani ${ }^{1}$, Dr. Kirit Sakariya ${ }^{2}$
}

${ }^{1}$ Assistant Professor, ${ }^{2}$ Associate Professor Department of Physiology PDU Govt. Medical College, Rajkot, Gujarat, India

\author{
DOI: $10.36348 /$ sijap.2019.v02i11.002 $\quad$ | Received: 28.10.2019| Accepted: 06.11.2019| Published: 14.11 .2019 \\ *Corresponding author: Dr. Kirit Sakariya
}

\section{Abstract}

Background: Obesity is a complex, multi-factorial, chronic condition that is associated with mortality and significant morbidity and is prevalent worldwide. The aim of the study is to determine the effect of obesity on pulmonary function abnormality in young adults in our population. Method: A cross sectional study on 140 individuals, selected randomly from general population of Rajkot city was performed. A thorough history analysis (Height, Weight, BMI), Physical examinations Spirometry were done on all individuals after explaining the procedure and taking their consent. Parameters measured by the spirometer were FEV1, FVC, FEV1/FVC, PEFR, ERV, IC, EC, VC. Result \& conclusion: It was observed that lung volumes decreased with statistically significant decreased ERV $(0.66 \pm 0.09$ L) \& FVC $(3.10 \pm 0.91)$ as the BMI increases $\left(30-35 \mathrm{Kg} / \mathrm{m}^{2}\right)$. Negative correlation was found between BMI and ERV $(-0.307)$ at higher BMI Values. Keywords: Obesity, Body mass index, pulmonary function tests.

Copyright @ 2019: This is an open-access article distributed under the terms of the Creative Commons Attribution license which permits unrestricted
use, distribution, and reproduction in any medium for non-commercial use (NonCommercial, or CC-BY-NC) provided the original author and source
are credited.

\section{INTRODUCTION}

Obesity is a complex, multi-factorial, chronic condition that is associated with mortality and significant morbidity and is prevalent worldwide [10]. The prevalence of obesity is increasing to very rapid proportions at an alarming rate in both developed and under developed countries around the world [9]. An increase in the prevalence of obesity in young adults has been seen around the world [2]. Body mass index (BMI; in $\mathrm{kg} / \mathrm{m} 2$ ) is widely used for the classification of overweight (BMI 25-30 kg/m2) and obesity (BMI > 30 $\mathrm{kg} / \mathrm{m} 2$ ) in men and women. BMI correlates reasonably well with laboratory-based measures of adiposity [4], and is extremely practical in most clinical settings for population studies.

Multiple measures of adiposity showed a significant inverse relationship with both static lung volumes and spirometry. In adults, pulmonary function abnormalities are well reported complications of obesity; the most frequently reported abnormalities are decrease in lung volumes and expiratory flow rates [5, 6].

Thus, the aim of the study is to determine the effect of obesity on pulmonary function abnormality in young adults in population of Rajkot city, Gujarat (India).

\section{MATERIAL AND METHODS}

Study was performed on 140 healthy, asymptomatic young individuals in the age group of 18 to 24 yrs selected from community. Individuals doing regular exercise, having respiratory infections or any other respiratory diseases, smokers, hypertensive, or having any musculoskeletal deformities of chest or vertebral column were excluded from the study.

The subjects, to be enrolled for the study, were informed about the study and procedure details and an informed consent was obtained. The subjects were all healthy asymptomatic.

All participants provided information on age, personal habits (alcohol intake, tobacco consumption, type and level of physical exercise, drug ingestion, known pathological conditions), and family history. A detailed physical examination was conducted to exclude pulmonary diseases or cardiac diseases. Our study was reviewed and approved by the Institutional Ethics Committee.

Anthropometric variables like height and weight were collected. Height was measured to the nearest of $0.1 \mathrm{~cm}$ and weight was measured to the nearest of $0.1 \mathrm{~kg}$ with of clothes and no shoes. Body mass index was calculated by Quetelet's Index [3]. 
Pulmonary functions were recorded on a computerized portable lung function unit SP-1. The recorded parameters were compared with the inbuilt pulmonary function norms for the Indian population depending upon the age, sex, height, and weight. Recording of static and dynamic pulmonary function tests was conducted on motivated young healthy volunteers in standing position [15].

These tests were recorded at noon before lunch, as expiratory flow rates are highest at noon. For each volunteer three satisfactory efforts were recorded according to the norms given by American Thoracic Society [1]. The essential parameters obtained were, tidal volume (VT), expiratory reserve volume (ERV), inspiratory capacity (IC), forced vital capacity (FVC), timed vital capacity (FEV1), maximum ventilator volume (MVV) and peak expiratory flow rate (PEFR).

\section{RESULT}

The effect of body mass index on ventilatory lung function tests were compared in control (BMI 18$25 \mathrm{Kg} / \mathrm{m}^{2}$ ), overweight (BMI $25-30 \mathrm{Kg} / \mathrm{m}^{2}$ ) and obese group (BMI $>35 \mathrm{Kg} / \mathrm{m}^{2}$ ) groups by the unpaired $\mathrm{T}$ test. Data were expressed as Mean \pm SD. Statistical significance was indicated by ' $\mathrm{P}$ ' value $<0.05$. Correlation of ventilatory lung function tests with body mass index was done by using Pearson's correlation coefficient test. The non-zero values of ' $r$ ' between -1 to 0 indicate negative correlation.

Table-1: Comparision of mean \pm sd values of anthropometric parameters of three groups of volunteers

\begin{tabular}{|c|c|c|c|}
\hline Parameters & $\begin{array}{l}\text { Control } \\
\left(18-25 \mathrm{Kg} / \mathrm{m}^{2}\right)\end{array}$ & $\begin{array}{l}\text { Overweight } \\
\left(25-30 \mathrm{Kg} / \mathrm{m}^{2}\right)\end{array}$ & $\begin{array}{l}\text { Obese } \\
\left(>30 \mathrm{Kg} / \mathrm{m}^{2}\right)\end{array}$ \\
\hline Age (Years) & $19 \pm 1.3$ & $21.67 \pm 2.17$ & $22.47 \pm 1.77$ \\
\hline Height (cm) & $170.7 \pm 7.18$ & $167 \pm 3.70$ & $165.8 \pm 4.45$ \\
\hline Weight $(\mathrm{Kg})$ & $60.50 \pm 11.49$ & $80 \pm 5.7$ & $84.43 \pm 4.58$ \\
\hline BMI $\left(\mathrm{Kg} / \mathrm{m}^{2}\right)$ & $20.65 \pm 3.03$ & $28.56 \pm 2.27$ & $32.81 \pm 0.73$ \\
\hline
\end{tabular}

Table-2: Comparision of mean \pm sd values of pulmonary function tests amongst the control, overweight and obese

\begin{tabular}{|c|c|c|c|}
\hline \multicolumn{4}{|c|}{ groups } \\
\hline Parameters & $\begin{array}{l}\text { Control } \\
\left(18-25 \mathrm{Kg} / \mathrm{m}^{2}\right)\end{array}$ & $\begin{array}{l}\text { Overweight } \\
\left(25-30 \mathrm{Kg} / \mathrm{m}^{2}\right)\end{array}$ & $\begin{array}{l}\text { Obese } \\
\left(>30 \mathrm{Kg} / \mathrm{m}^{2}\right)\end{array}$ \\
\hline ERV (L) & $1.045 \pm 0.49$ & $0.74 \pm 0.064$ & $0.66 \pm 0.096^{*}(\mathrm{p}=0.0167)$ \\
\hline $\mathrm{IC}(\mathrm{L})$ & $3.32 \pm 0.17$ & $3.14 \pm 0.34$ & $3.11 \pm 0.35$ \\
\hline $\mathrm{FVC}(\mathrm{L})$ & $3.67 \pm 0.41$ & $3.71 \pm 0.32$ & $3.10 \pm 0.51 *(\mathrm{p}=0.0437)$ \\
\hline FEV1/FVC & $0.79 \pm 0.022$ & $0.81 \pm 0.020$ & $0.80 \pm 0.02$ \\
\hline MVV(L/min) & $121 \pm 32.16$ & $122.2 \pm 12.68$ & $117.8 \pm 8.6$ \\
\hline PEFR(L/min) & $428.6 \pm 66.15$ & $426.2 \pm 98.68$ & $439.7 \pm 63.48$ \\
\hline FEF25-75\%(L/sec) & $4.92 \pm 0.14$ & $4.95 \pm 0.0089$ & $4.98 \pm 0.10$ \\
\hline
\end{tabular}

Table-3: Correlation of bmi and pulmonary function tests

\begin{tabular}{|l|l|l|l|l|l|l|l|}
\hline BMI & ERV (L) & IC(L) & FVC(L) & FEV1/FVC & MVV(L/min) & $\begin{array}{l}\text { PEFR } \\
(\mathbf{L} / \mathbf{m i n})\end{array}$ & $\begin{array}{l}\text { FEF 25- } \\
\mathbf{7 5 \%}\end{array}$ \\
\hline $18-25 \mathrm{Kg} / \mathrm{m} 2$ & 0.4644 & 0.3128 & 0.1159 & 0.2504 & 0.1759 & 0.071 & 0.031 \\
\hline $25-30 \mathrm{Kg} / \mathrm{m} 2$ & 0.33 & 0.061 & $\begin{array}{l}-0.183^{*} \\
(\mathrm{p}=0.02)\end{array}$ & 0.128 & 0.013 & 0.25 & 0.071 \\
\hline$>30 \mathrm{Kg} / \mathrm{m} 2$ & $\begin{array}{l}-0.307^{*} \\
(\mathrm{p}=0.018)\end{array}$ & 0.25 & $\begin{array}{l}-0.35^{*} \\
(\mathrm{p}=0.016)\end{array}$ & 0.166 & 0.12 & 0.274 & 0.194 \\
\hline
\end{tabular}

$$
* \mathrm{p} \text { value }<0.05
$$

In this study we have made a correlation of BMI and pulmonary function tests by dividing subjects in three groups. Significant decrease in ERV and FVC was observed in obese group in comparison to control subjects. Many previous studies also observed that increased BMI is associated with decreased ERV, as seen in our study also [11].

\section{DISCUSSION}

The present study demonstrated the relationship between pulmonary function and BMI in young males in age group 18-25 yrs. collected data were analysed by comparing BMI and their relationship with pulmonary functions in young individuals.

In the present study it was observed that increase in Body Mass Index is associated with significant decrease in Expiratory Reserve Volume. Inverse relationship of BMI with FVC was observed in the present study. There was no significant correlation of BMI and IC, FEV1/FVC, MVV, PEFR and FEF25$75 \%$. 
Richard L. Jones et al. also observed that increase in BMI is associated with decreased ERV [12] Many other studies have also noted that increased BMI have most dramatic reduction of ERV [7, 13]. Sahebjami $\mathrm{H}$ et al. also confirms decreased ERV with increased BMI [14]. Wannamethee et al. observed that BMI showed no significant correlation with FEV1 but was inversely correlated with FVC [16].

BMI is a global measure of body fat mass that includes both fat and lean mass. BMI does not measure differences in fat distribution. Body mass index has been proposed to analyse the effects of increased weight on pulmonary function tests, but its use is only valid for lung function indices where the contribution of fat and muscles are synergistic.

The site of fat accumulation is crucial in determining the effect of obesity on respiratory system mechanics. BMI alone does not provide enough information about the body distribution of fat mass [6]. Mohan V. et al. also noted that Indians are considerably obese at low BMI [8]. So, the evaluation of the change in pulmonary function in overweight subjects should be done by estimating body fat percentage.

\section{REFERENCES}

1. Medical Section of the American Lung Association. (2012). American Thoracic Society Standardization of Spirometry, 1994 Update.

2. Biring, M. S., Lewis, M. I., Liu, J. T., \& Mohsenifar, Z. (1999). Pulmonary physiologic changes of morbid obesity. The American journal of the medical sciences, 318(5), 293-297.

3. Garrow, J. S., \& Webster, J. (1985). Quetelet's index (W/H2) as a measure of fatness. International journal of obesity, 9(2), 147153.

4. Allison, D. B., Allison, D. B., \& Baskin, M. L. (2009). Handbook of assessment methods for eating behaviors and weight-related problems: measures, theory, and research. Sage.

5. Koenig, S. M. (2001). Pulmonary complications of obesity. The American journal of the medical sciences, 321(4), 249-279.
6. Lazarus, R., Sparrow, D., \& Weiss, S. T. (1997). Effects of obesity and fat distribution on ventilatory function: the normative aging study. Chest, 111(4), 891-898.

7. McClean, K. M., Cardwell, C. R., \& Kee, F. (2007). Longitudinal change in BMI and lung function in middle-aged men in Northern Ireland. Ir J Med Sci, 176(Suppl 10), S418.

8. Mohan, V., \& Deepa, R. (2006). Obesity and abdominal obesity in Asian Indians. The Indian journal of medical research, 123(5), 593-6.

9. Mokdad, A. H., Serdula, M. K., Dietz, W. H., Bowman, B. A., Marks, J. S., \& Koplan, J. P. (1999). The spread of the obesity epidemic in the United States, 1991-1998. Jama, 282(16), 15191522.

10. Popkin, B. M., Paeratakul, S., Zhai, F., \& Ge, K. (1995). A review of dietary and environmental correlates of obesity with emphasis on developing countries. Obesity Research, 3(S2), 145s-153s.

11. Ray, C. S., Sue, D. Y., Bray, G., Hansen, J. E., \& Wasserman, K. (1983). Effects of obesity on respiratory function. American Review of Respiratory Disease, 128(3), 501-506.

12. Jones, R. L., \& Nzekwu, M. M. U. (2006). The effects of body mass index on lung volumes. Chest, 130(3), 827-833.

13. Rubinstein, I., Zamel, N., DuBarry, L., \& Hoffstein, V. (1990). Airflow limitation in morbidly obese, nonsmoking men. Annals of Internal Medicine, 112(11), 828-832.

14. Sahebjami, H. (1998). Dyspnea in obese healthy men. Chest, 114(5), 1373-1377.

15. Townsend, M. C. (1984). Spirometric forced expiratory volumes measured in the standing versus the sitting posture. American Review of Respiratory Disease, 130(1), 123-124.

16. Wannamethee, S. G., Shaper, A. G., \& Whincup, P. H. (2005). Body fat distribution, body composition, and respiratory function in elderly men. The American journal of clinical nutrition, 82(5), 9961003. 